\title{
PARA O ESTUDO DA SAÚDE CONVENTUAL NO INÍCIO DO SÉCULO XIX: AS BOTICAS*
}

\author{
Ricardo Pessa de Oliveira**
}

Fundação Calouste Gulbenkian

\begin{abstract}
RESUMO
Em Novembro de 1789 foi criada a Junta do Exame do Estado Actual e Melhoramento Temporal das Ordens Regulares. Entre outros aspectos cada casa religiosa devia dar a conhecer à Instituição o seu património móvel e imóvel. De entre os bens inventariados contavam-se os pertencentes às enfermarias e boticas. No presente artigo pretendemos estudar estes espaços recorrendo a registos de uma série de casas religiosas escolhidas sem preferência regional ou Ordem religiosa. Tentaremos responder a questões tais como: quais os objetos que formavam estes espaços, se estariam bem apetrechados e ainda se existiriam grandes diferenças consoante Ordem religiosa e localização da Casa.
\end{abstract}

PALAVRAS CHAVE: Século XIX. Boticas. Casas Religiosas. Cultura Material. Farmacopéias.

\section{TO THE STUDY OF CONVENTUAL HEALTH IN THE BEGINNING OF $19^{\mathrm{TH}}$ CENTURY: THE PHARMACIES}

\begin{abstract}
The institution Junta do Exame do Estado Actual e Melhoramento Temporal das Ordens Regulares (Examination Council for the Actual State and Temporal Improvement of the Religious Orders) was created in November of 1789. Among other things, each Religious House should inform that institution about its heritage either the movables and the landed estates. The inventorying included all the goods belonging to wards and drugstores. In this paper we aim to study those places using records obtained from a variety of Religious Houses with no regional or Religious Order preferences. We will try to give answers to questions related to that spaces such as: "Which objects could be found inside the Houses?"; "Were they prorperly equiped?" and "Were there big differences between them in what concerns Religious Orders and Houses locations?"
\end{abstract}

KEY WORDS: $19^{\text {th }}$ century. Pharmacy. Religious Houses. Material Culture. Pharmacopoeias.

* Texto apresentado ao XXVIII Encontro da Associação de História Económica e Social (APHES), o qual teve lugar em Guimarães, Portugal, nos dias 21 e 22 de Novembro de 2008.

** Doutorando em História Moderna pela Faculdade de Letras da Universidade de Lisboa. Bolseiro da Fundação Calouste Gulbenkian, contacto: ricardo_pessa@sapo.pt. 


\section{INTRODUÇÃO}

A 21 de Novembro de 1789, foi criada a Junta do Exame do Estado Actual e Melhoramento Temporal das Ordens Regulares ${ }^{1}$. A instituição manteve-se em funcionamento até 1829, quando D. Miguel ordenou a sua extinção. Em Agosto de 1833, viria a ser restaurada por D. Pedro IV, sendo definitivamente abolida a 10 de Outubro de 1834, sem conseguir atingir os propósitos para os quais havia sido constituída ${ }^{2}$. No momento da sua criação foi nomeado presidente o bispo do Algarve, D. José Maria de Melo, que seria coadjuvado por seis deputados. O visconde de Vila Nova da Cerveira, D. Tomás Xavier de Lima Nogueira Vasconcelos Teles da Silva, ficou encarregue do expediente do despacho da instituição. Cada casa religiosa devia dar a conhecer à Junta o número de religiosos que possuía, qual o seu património móvel e imóvel, qual o valor das rendas bem como a sua natureza e quais as dívidas activas e passivas. Pretendia-se, pois, conhecer o estado dos conventos e mosteiros para uma posterior actuação, sobretudo no sentido de racionalizar aqueles espaços, suprimindo e unindo determinadas casas, quando tal se justificasse, tentando resolver os problemas financeiros das mesmas. De entre os bens inventariados contavam-se os pertencentes às sacristias, coros, celas, cozinhas ${ }^{3}$, refeitórios, ucharias, adegas, enfermarias e boticas. No artigo que ora se publica pretendemos estudar as boticas conventuais recorrendo a registos de uma série de casas religiosas escolhidas sem preferência regional ou de ordem religiosa. Tentaremos responder a questões tais como: quais os objetos que formavam estes espaços, estariam as boticas bem apetrechadas e ainda se existiriam grandes diferenças consoante as ordens religiosas e a localização da Casa.

A farmácia portuguesa de Seiscentos e Setecentos foi fortemente marcada pelas boticas conventuais. O número de casas religiosas que possuía tais espaços era elevado. Estas foram sendo instituídas desde cedo, muitas vezes destinadas a servir os hospitais dos conventos. Foi o caso da botica do mostei-

1 Cf. o decreto de D. Maria I que instituiu a Junta em Silva, A.D. (1974), Collecção de Legislação Portugueza, desde a ultima compilação das Ordenações, 1775 a 1790, Lisboa, Tipografia Maigrence, pp. 572-574; CorreIA, J.E.H. (1974), Liberalismo e Catolicismo. O Problema Congreganista (1820-1823), Coimbra, Universidade de Coimbra, , pp. 261-263.

2 Abreu, L. (2004), Um Parecer da Junta de Exame do Estado Actual e Melhoramento Temporal das Ordens Regulares nas Vésperas do Decreto de 30 de Maio de 1834. En Estudos em Homenagem a Luís António de Oliveira Ramos, vol. 1, Porto, Faculdade de Letras da Universidade do Porto, pp. 117-130; BRAGA, I.M.D. (2007), Para o estudo da bateria de cozinha conventual no início do século XIX, Lusíada, História, n. ${ }^{\circ}$ 4, p. 206.

3 BRAGA (2007), pp. 201-225. 
ro de São Vicente de Fora que terá sido criada em simultâneo com o hospital no ano de $1182^{4}$. Entre as boticas de maior importância e prestígio contavamse as dos cônegos regulares de Santo Agostinho, nomeadamente a do mosteiro de Santa Cruz de Coimbra, a já referida de São Vicente de Fora ${ }^{5}$ e a do convento de Mafra ${ }^{6}$. Mas muitas outras ordens possuíram importantes boticas, tais como dominicanos ${ }^{7}$, jesuítas ${ }^{8}$, carmelitas, beneditinos $^{9}$ e oratorianos. Refira-se ainda que algumas casas religiosas femininas, como as carmelitas do convento do Carmo de Tentúgal, usufruíram igualmente de botica ${ }^{10}$. Não obstante o quase monopólio das boticas conventuais, muitas comunidades religiosas, sobretudo femininas, continuavam a recorrer a boticas leigas ${ }^{11}$. As

4 Basso, P. e Neto, J. (1994), O Real Mosteiro de São Vicente de Fora. In A Botica de São Vicente de Fora, Lisboa, Associação Nacional das Farmácias, p. 13.

5 Basso e Neto (1994), pp. 13-17; Dias, J.P.S. e PitA, R. (1994), A Botica de São Vicente e a Farmácia nos mosteiros e conventos da Lisboa Setecentista. In A Botica de São Vicente de Fora, Lisboa, Associação Nacional das Farmácias, pp. 19-25.

6 Carvalho, A. (1948), A antiga botica do convento de Mafra e o material actualmente existente. In Actas do I Congresso Luso-Espanhol de Farmácia, Lisboa, Coimbra Editora, pp. 1-26 (citado pela separata). Sobre boticas dos frades crúzios cf. ainda SilvA, A.C.C. (1972), Inventário de uma botica conventual do século XVIII, Anais da Faculdade de Farmácia do Porto, XXXII, pp. 9-37 (citado pela separata); MARQUeS, J. (2008), A botica do mosteiro de Santa Maria de Landim - 1770. In Actas do III Encontro Cultural de São Cristóvão de Lafões, (Mosteiro e Saúde. Cerca, botica e enfermaria), São Cristóvão de Lafões, Sociedade do Mosteiro de São Cristóvão de Lafões, pp. 25-58. Ambos os textos utilizaram como fonte os inventários levados a cabo aquando da extinção de nove mosteiros dos cónegos regrantes em benefício do convento de Mafra, supressão de que foi juiz D. João Cosme da Cunha. Sobre esta figura cf. Oliveira, R.P. (2007), Uma Vida no Santo Oficio: o Inquisidor Geral D. João Cosme da Cunha, Lisboa, Dissertação de Mestrado em História Moderna apresentada à Faculdade de Letras da Universidade de Lisboa, exemplar mimeografado.

7 Dias, J.P.S. (1986), A botica do Convento de São Domingos de Lisboa num poema de Serrão de Castro (finais do século XVII), Farmácia Portuguesa, 37, pp. 46-47.

8 Sobre a botica inaciana do Colégio de Santo Antão cf. DiAS e PITA (1994), pp. 21-22.

9 Sobre a botica do Mosteiro de Tibães cf. MATA, A.M.R. (1992), A Botica de Tibães. In A Botica, séculos XVII-XVIII, Catálogo da Exposição, Braga, Instituto Português de Museus, Museu dos Biscainhos, Museu do Mosteiro de São Martinho de Tibães, pp. não numeradas. A propósito das boticas dos mosteiros beneditinos existe um estudo inédito, ao qual não tivemos acesso, da autoria de Afonso, M.P.M.B. (1991), As boticas da Congregação de São Bento de Portugal, Porto, Universidade Portucalense.

10 Dias e Pita (1994), pp. 19-20.

11 Cf. Dias, J.P.S. (2007), Droguistas, Boticários e Segredistas. Ciência e Sociedade na Produção de Medicamentos na Lisboa de Setecentos, Lisboa, Fundação Calouste Gulbenkian, Fundação para a Ciência e a Tecnologia, p. 151. 
clarissas do convento de Nossa Senhora dos Poderes, de Via Longa, deviam em 1823, ao boticário Alexandre de Freitas 107.105 réis, ao boticário de Alverca 1.700 réis e ao boticário de Via Longa 81.800 réis $^{12}$. Também os religiosos do convento do Santíssimo Sacramento da Ordem de São Paulo, de Lisboa, deviam ao boticário João Evangelista Guerreiro de medicamentos «athe ao fim do primeiro trimestre deste anno [1823], settenta mil réis em papel, e vinte mil seiscentos e vinte réis na forma» ${ }^{13}$. A despesa deste convento em botica foi estimada em 100.000 réis por ano sendo que «excede quazi todos os annos» ${ }^{14}$.

\section{BOTICAS E BOTICÁRIOS}

A documentação consultada, produzida no ano de 1823, deu conta de nove boticas conventuais de diversas Ordens religiosas, todas elas masculinas. Como se pode observar no quadro 1 , temos quatro boticas pertencentes à Ordem do Carmo, duas à Ordem de São Domingos, igual número à Ordem de São Bento e uma à Terceira Ordem da Penitência de São Francisco. No que diz respeito à localização dos conventos e mosteiros temos cinco na região de Lisboa, três no Norte do país e um no Sul de Portugal.

QUADRO 1. CASAS RELIGIOSAS

\begin{tabular}{|l|l|l|}
\hline Convento & Localização & Ordem \\
\hline $\begin{array}{l}\text { Convento de São João da } \\
\text { Pesqueira }\end{array}$ & São João da Pesqueira & $\begin{array}{l}\text { Terceira Ordem da Penitência } \\
\text { de São Francisco }\end{array}$ \\
\hline $\begin{array}{l}\text { Convento Carmelitas Des- } \\
\text { calços de Tavira }\end{array}$ & Tavira & $\begin{array}{l}\text { Ordem do Carmo } \\
\text { (Carmelitas Descalços) }\end{array}$ \\
\hline Convento Corpus Christi & $\begin{array}{l}\text { Lisboa, Rua dos Fan- } \\
\text { queiros }\end{array}$ & $\begin{array}{l}\text { Ordem do Carmo } \\
\text { (Carmelitas Descalços) }\end{array}$ \\
\hline $\begin{array}{l}\text { Convento Nossa Senhora } \\
\text { dos Remédios }\end{array}$ & $\begin{array}{l}\text { Lisboa, Rua das Jane- } \\
\text { las Verdes }\end{array}$ & $\begin{array}{l}\text { Ordem do Carmo } \\
\text { (Carmelitas Descalços) }\end{array}$ \\
\hline $\begin{array}{l}\text { Mosteiro Santo André } \\
\text { Rendufe }\end{array}$ & Rendufe (Amares) & $\begin{array}{l}\text { São Bento } \\
\text { (Beneditinos) }\end{array}$ \\
\hline
\end{tabular}

12 Lisboa, Arquivo Nacional Torre do Tombos (A.N.T.T.), Ministério dos Negócios Eclesiásticos e Justiça (MNEJ), caixa 225, maço 280.

13 Lisboa, A.N.T.T., MNEJ, caixa 188, maço 234.

14 Lisboa, A.N.T.T., MNEJ, caixa 188, maço 234. 


\begin{tabular}{|l|l|l|}
\hline Convento & Localização & Ordem \\
\hline Mosteiro de Paço de Sousa & $\begin{array}{l}\text { Paço de Sousa (Pena- } \\
\text { fiel) }\end{array}$ & $\begin{array}{l}\text { São Bento } \\
\text { (Beneditinos) }\end{array}$ \\
\hline $\begin{array}{l}\text { Convento de São Domin- } \\
\text { gos }\end{array}$ & Lisboa, Rossio & $\begin{array}{l}\text { São Domingos } \\
\text { (Dominicanos) }\end{array}$ \\
\hline Convento de São Sebastião & Setúbal & $\begin{array}{l}\text { São Domingos } \\
\text { (Dominicanos) }\end{array}$ \\
\hline $\begin{array}{l}\text { Convento de Nossa Sen- } \\
\text { hora da Piedade }\end{array}$ & Cascais & $\begin{array}{l}\text { Ordem do Carmo } \\
\text { (Carmelitas Descalços) }\end{array}$ \\
\hline
\end{tabular}

Fonte: Lisboa, A.N.T.T., MNEJ, caixa 184, maço 229; caixa 187, maço 233, n. ${ }^{\circ} 1-3$; caixa 225 , maço 280; caixa 229, maço 283; caixa 231, maço 285.

A 25 de Janeiro de 1823, José da Silva Carvalho a quem fora confiada a pasta dos Negócios Eclesiásticos e da Justiça no ano de 1821, assinou umas Instruções para os inventários das casas religiosas. $\mathrm{O}$ artigo $\mathrm{n}^{\circ} 3$ do documento mencionava que o juiz havia de descrever em primeiro lugar o convento com todos os seus lugares regulares, como o número de celas, acomodações, oficinas e mais casas, dando conta do estado em que as mesmas se encontravam. Nestas descrições encontramos algumas referências às boticas, ainda que na maior parte dos casos não refiram nada de extraordinário. Sobre o convento de São João da Pesqueira o inventariante apenas referiu existir uma botica com seu armazém ${ }^{15}$. O convento de Nossa Senhora da Piedade da vila de Cascais tinha no «baixo [do mesmo] as commudidades seguintes: hum refeitorio, huma cozinha, huma caza que cerve de adega e celeiro, pegada com esta caza está outra que serve de amacaria e pegadas a estas está huma caza que cerve de botica» ${ }^{16}$. São Domingos possuía uma casa de botica e outras duas casas onde se guardavam os utensílios ${ }^{17}$. Já o juiz que procedeu ao inventário do convento de Corpus Christi em Lisboa refere algo de maior importância uma vez que deu conta de uma casa de botica e uma casa de destilação da mesma ${ }^{18}$. O convento de São Sebastião possuía uma botica com laboratório ${ }^{19}$. Não obstante, tal não significa que esta botica não adquirisse remédios já preparados. Em meados de Setecentos a botica do Colégio de

15 Lisboa, A.N.T.T., MNEJ, caixa 184, maço 229.

16 Lisboa, A.N.T.T., MNEJ, caixa 231, maço 285.

17 Lisboa, A.N.T.T., MNEJ, caixa 225, maço 280.

18 Lisboa, A.N.T.T., MNEJ, caixa 184, maço 229.

19 Lisboa, A.N.T.T., MNEJ, caixa 225, maço 280. 
Santo Antão apesar de ter sala própria para a preparação de medicamentos adquiria grandes porções de substâncias químicas já preparadas. Tal facto prova que mesmo dispondo da logística exigida para a manipulação química nem sempre se faria uso da mesma, de forma constante ${ }^{20}$.

No que respeita aos padres boticários conhecemos alguns dos seus nomes e qualidades científicas. O encarregado da botica do convento de Nossa Senhora dos Remédios era frei José de São Domingos ${ }^{21}$. O padre boticário do mosteiro beneditino de Paço de Sousa era frei Manuel de Santa Catarina ${ }^{22}$. Frei José dos Remédios era o boticário do convento do Carmo de Tavira ${ }^{23}$. Frei António de Jesus Maria era boticário no Convento de Corpus Christi2 ${ }^{24}$. É difícil avaliar os conhecimentos e o nível científico dos padres boticários. Ainda assim conseguimos recolher alguns dados que revelam alguns pormenores a esse respeito. Do boticário do convento de Nossa Senhora da Piedade escreveu-se ser de muito boa instrução na química e na botânica ${ }^{25}$. Numa referência aos religiosos hábeis do convento do Carmo de Tavira foi mencionado o padre boticário frei José dos Remédios, como sendo igualmente muito hábil nestas duas disciplinas ${ }^{26}$. Os conhecimentos científicos destes padres foram tão mais importantes se tivermos em conta o importante contributo que deram na produção literária farmacêutica, de que se destaca, pelo seu pioneirismo, a Pharmacopea Lusitana da autoria de D. Caetano de Santo António.

Mas os funcionários destas boticas não eram unicamente religiosos. Por exemplo, numa relação de 1790, sobre os criados do convento dos religiosos Carmelitas Descalços de Nossa Senhora do Monte do Carmo, situado em Aveiro, entre lavradores, forneiro, almocreve e horticultor contavam-se dois praticantes da botica, a saber um José Caetano e um tal António, os quais auferiam 14.400 réis anuais ${ }^{27}$. Em 1823, a comunidade de São Domingos de Lisboa despendia 259.200 réis com as quatro pessoas que trabalhavam na sua botica $^{28}$. O número de elementos que trabalhavam nas boticas conventuais comprova por si só a real importância destes espaços.

\footnotetext{
20 DiAs (2007), pp. 124 e 126.

21 Lisboa, A.N.T.T., MNEJ, caixa 184, maço 229.

22 Lisboa, A.N.T.T., MNEJ, caixa 187, maço 233, n. ${ }^{\circ}$ 1-3.

23 Lisboa, A.N.T.T., MNEJ, caixa 184, maço 229.

24 Lisboa, A.N.T.T., MNEJ, caixa 184, maço 229.

25 Lisboa, A.N.T.T., MNEJ, caixa 231, maço 285.

26 Lisboa, A.N.T.T., MNEJ, caixa 184, maço 229.

27 Lisboa, A.N.T.T., MNEJ, caixa 231, maço 285.

28 Lisboa, A.N.T.T., MNEJ, caixa 225, maço 280.
} 


\section{O PATRIMÓNIO DAS BOTICAS}

Francisco Tavares na Pharmacopea Geral de 1794 enunciou o equipamento que cada botica deveria possuir. Este deveria constar de alambiques, almofarizes, balanças, coadores, espátulas, colheres, escumadeiras, funis, fornos, garrafas, prensas, panelas, peneiros, pedras de preparo, retortas, tachos e vasos ${ }^{29}$.

Em todas as boticas estudadas existiam grandes quantidades de vasos de diversos tamanhos, feitios e cores. Temos vasos de pó de pedra, de vidro, de louça e de barro. De entre os vasos de vidro contavam-se as chamadas redomas, de gargalo comprido e estreito, e de bojo largo, e as cacetas. Quanto às cores predominavam os azuis e brancos. Os vidros de botica existiam igualmente em enormes porções. O convento de Nossa Senhora dos Remédios era detentor de 530 vidros entre sortidos (220), grandes (180) e pequenos (130) que valiam um total de 33.300 réis. O convento de Corpus Christi tinha 238 vidros sorteados, de diversos tamanhos avaliados em 19.040 réis. Já o convento de São João da Pesqueira possuía 173 vidros pequenos com rolha do mesmo material avaliados em 27.680 réis. Cada botica possuía igualmente almofarizes e alambiques. Os primeiros foram inventariados como sendo de diversos materiais e formas, existindo os de vidro, de bronze, de cobre, de chumbo, de ferro, de mármore e ainda os de chumbo com mão de marfim, de marfim com mão de madeira e os de pedra não especificada. $\mathrm{O}$ convento de São João da Pesqueira foi aquele em que foi registado um maior número destes instrumentos, a saber dez. Quanto aos alambiques, estes eram na maioria das vezes de cobre mas também de lata ou de folha. Em cinco boticas foram catalogados grais de pedra, vidro e marfim. Destaque para a botica do convento de São Domingos de Lisboa que possuía oito grais, a saber cinco de pedra, dois de marfim e um de vidro, que em conjunto importavam 580 réis. Em alguns destes espaços foram registadas prensas e mesas de laboratório. O convento de São João da Pesqueira possuía uma prensa de madeira avaliada em 4.800 réis, bem como uma mesa de laboratório no valor de 1.600 réis. Os religiosos de Tavira dispunham de uma prensa de parafuso de ferro no valor de 6.400 réis, já o convento de Nossa Senhora da Piedade era proprietário de uma prensa que, devido ao seu mau estado, foi avaliada em 800 réis. Para obtenção das mezinhas e manipulação das drogas existiam ainda peneiras, tamises e sedaços, raladores, escumadeiras, espátulas, fogareiros e candeeiros. Em boa parte dos conventos encontramos também açucareiros, alguidares,

29 Pita, J.R (1996), Farmácia, Medicina e Saúde Pública em Portugal (1772-1836), Coimbra, Minerva Editora, p. 216. 
bacias, bilhas, canecos, cântaros, colheres, copos, facas, frascos, funis, garrafas, latas, panelas, pires, potes, púcaros, tachos e tesouras.

Entre os objetos pouco comuns contaram-se três pedras de preparo e duas retortas pertencentes à botica do convento Corpus Christi em Lisboa ${ }^{30}$; quatro pratos, igual número de comadres, três seringas, uma pedra para emplastros, um termómetro, um crivo, um machado, um martelo e um esquentador tudo pertencente à farmácia conventual de São Domingos de Lisboa ${ }^{31}$.

Indispensáveis em qualquer botica eram as balanças, os pesos e as medidas $^{32}$. Estabelecidos pelas Ordenações do Reino, o conjunto de pesos e medidas pertencentes aos boticários leigos deviam ser aferidos duas vezes ao ano. Não obstante, as boticas conventuais estavam livres desta obrigatoriedade. Nos conventos estudados existiam balanças de diversos tamanhos e feitios. Neste particular destaque para o convento de Nossa Senhora da Piedade que possuía quatro balanças avaliadas em 9.600 réis. No que respeita aos pesos utilizados temos os de arrátel (0,459 quilos) e os de meio arrátel (0, 230 quilos), sendo que o arrátel árabe pesava $12 \frac{1}{2}$ onças. Existiam ainda medidas de libra $(0,489$ ou 0,326 quilos), meia libra ( 0,244 ou 0,163 quilos), onça $(0,029$ quilos) e meia onça ( 0,014 quilos).

A armação da botica, nos casos em que foi inventariada, representou sempre uma elevada percentagem do valor total da farmácia. Entre as armações destaque para a pertencente ao convento do Corpus Christi em Lisboa, avaliada em 60.000 réis, que correspondia a $45.5 \%$ do valor total. Esta era «constante de duas cazas, a saber parteleiras em roda da casa e gavetas por baixo e um frontispicio com duas portas de entrada, huma urna no meio, e na casa anterior he composta de parteleiras e gavetas e hum balcao tudo para as acomodações de utensilios da mesma botica, tudo em madeira de pinho com alguns doirados, huma banca e huma cadeira com assento de coiro» ${ }^{33}$. De menor percentagem na avaliação geral era a armação da botica do convento do Carmo de Tavira que, não obstante o bom estado de conservação, foi somente avaliada em 19.200 réis. Do mesmo valor era a armação da botica do conven-

30 Lisboa, A.N.T.T., MNEJ, caixa 184, maço 229.

31 Lisboa, A.N.T.T., MNEJ, caixa 225, maço 280.

32 Sobre pesos e medidas cf. Marques, A.H.O. (1981), Pesos e Medidas. In SERrÃo, J. (dir.), Dicionário de História de Portugal, vol. V, Porto, Livraria Figueirinhas, pp. 67-72; BRAGA, I.M.D. (1988), A Circulação e a Distribuição dos Produtos. In SERRÃo, J. e MARQueS, A.H.O. (dir.), Nova História de Portugal, Vol. V, Do Renascimento à Crise Dinástica, Lisboa, Editorial Presença, pp. 207-208. Sobre este assunto nas boticas cf. DiAS (2007), pp. 209-213.

33 Lisboa, A.N.T.T., MNEJ, caixa 184, maço 229. 
to de Nossa Senhora dos Remédios. O restante mobiliário desta casa compreendia três bancos, um armário, uma urna e uma banca avaliado tudo em 2.920 réis. O mobiliário da botica do mosteiro de Santo André de Rendufe consistia em estantes, mostrador e gavetas num valor de 24.000 réis, um contador velho avaliado em 600 réis e uma mesa muito velha estimada em 240 réis. A mobília de botica de São Domingos de Lisboa era composta por seis tamboretes, duas mesas de pau e um banco de encosto. A madeira de que se compunham as estantes da botica do convento de Nossa Senhora da Piedade foi avaliada em 100.000 réis. Se o mobiliário, ou casco, da botica era importante para exteriorizar o estatuto do boticário ${ }^{34}$, existiam outros objetos que serviam o mesmo propósito. A botica do convento de São João da Pesqueira possuía uma pintura avaliada em 96.000 réis e um relógio de parede, com caixa pintada e dourada, no valor de 40.000 réis.

Em dois inventários surgiram têxteis pertencentes à botica. No mosteiro de Santo André de Rendufe foram registados cinco coadores de lã e um de linho para coar os remédios. No convento de São Domingos existiam 13 toalhas de linho para barba e seis panos destinados ao mesmo fim.

No que diz respeito às drogas existentes nas boticas e nos armazéns das mesmas os registos são particularmente pobres. Nos inventários dos conventos de São Francisco de São João da Pesqueira, Carmelitas Descalços de Tavira, Carmelitas Descalços de Nossa Senhora da Piedade, São Domingos de Lisboa, São Sebastião e no do mosteiro de Paço de Sousa apenas foi indicado o valor total das drogas - 300.000, 160.000, 100.000, 72.000, 60.000 e 35.000 réis respectivamente, sem individualizar as designações e qualidades das mesmas $^{35}$. Noutros casos as drogas, atendendo ao baixo valor, não foram sequer alvo de avaliação. Foi o caso do convento do Corpus Christi cujos boticários declararam existirem algumas drogas e medicamentos «que visto o continuo giro dos mesmos não merecem avaliação porque tem pouco ou quazi nenhum valor» ${ }^{36}$. As drogas eram adquiridas aos droguistas ou a outras boticas. Os religiosos do convento de Nossa Senhora do Monte do Carmo de Aveiro deviam de drogas um total de 280.650 réis, a saber 237.270 réis ao droguista Luís António Gomes Correia, residente na cidade do Porto, 28.800 réis à botica da cidade de Coimbra e 14.580 réis à botica da cidade do Porto ${ }^{37}$.

34 DIAS (2007), p. 165.

35 Lisboa, A.N.T.T., MNEJ, caixa 184, maço 229; caixa 187, maço 233, n. ${ }^{\circ} 1-3$; caixa 225, maço 280; caixa 231, maço 285.

36 Lisboa, A.N.T.T., MNEJ, caixa 184, maço 229.

37 Lisboa, A.N.T.T., MNEJ, caixa 231, maço 285. 
Em 1823, a divida da botica de São Domingos de Lisboa era de 777.600 réis. Os seus fornecedores haviam sido João Nepomeceno (508.500), o italiano que tivera loja às Convertidas ${ }^{38}$ João André Penco (120.880), Nicolau Unheco (76.220) e Vicente Joaquim (72.000) ${ }^{39}$. Por seu turno a botica do convento do Carmo de Tavira devia 180.000 réis ao droguista ${ }^{40}$ e a do convento de São Sebastião de Setúbal devia a um profissional do mesmo sector 47.000 réis $^{41}$.

QUADRO 2. VALOR DAS BOTICAS CONVENTUAIS

\begin{tabular}{|l|c|}
\hline Convento & Valor (réis) \\
\hline Convento de São João da Pesqueira & 645.950 \\
\hline Convento Carmelitas Descalços de Tavira & 284.840 \\
\hline Convento Corpus Christi & 131.920 \\
\hline Convento Nossa Senhora dos Remédios & 128.600 \\
\hline Mosteiro Santo André Rendufe & 84.380 \\
\hline Mosteiro de Paço de Sousa & 81.000 \\
\hline Convento de São Domingos & 210.090 \\
\hline Convento de São Sebastião & 139.310 \\
\hline Convento de Nossa Senhora da Piedade & 344.420 \\
\hline
\end{tabular}

Fonte: Lisboa, A.N.T.T., MNEJ, caixa 184, maço 229; caixa 187, maço 233, n. ${ }^{\circ} 1-3$; caixa 225, maço 280; caixa 229, maço 283; caixa 231, maço 285 .

A botica cujo património foi avaliado numa quantia mais elevada foi a do convento de São João da Pesqueira, seguida da do convento de Nossa Senhora da Piedade. No extremo oposto encontrava-se a botica do mosteiro de Paço de Sousa. Não passa despercebido o facto de as boticas dos três conventos de Lisboa terem sido avaliadas com valores muito inferiores às duas primeiras. Porém há que ter em conta que o valor da botica do convento de São Domingos não compreende a imensa biblioteca farmacêutica, algum mobiliário, tal como duas mesas de pau e seis tamboretes e ainda outros objetos como um ralador de folha e duas mãos de ferro de almofariz. Como tal, não restam dúvidas de que o seu valor real seria consideravelmente mais elevado. Por outro lado, estranhamos que no inventário do convento Corpus Christi e no de

\footnotetext{
38 DIAS (2007), p. 324.

39 Lisboa, A.N.T.T., MNEJ, caixa 225, maço 280.

40 Lisboa, A.N.T.T., MNEJ, caixa 184, maço 229.

41 Lisboa, A.N.T.T., MNEJ, caixa 225, maço 280.
} 
Nossa Senhora dos Remédios não existam instrumentos essenciais como balanças, pesos e medidas, o que poderá sugerir que estas boticas estivessem já, ou perto de serem, desactivadas.

Se tivermos em conta a Ordem a que pertencia cada botica verificamos que as dominicanas de São Domingos e São Sebastião apresentaram valores relativamente próximos. Tal facto é ainda mais evidente no que toca às boticas da Ordem de São Bento, onde a diferença entre as duas estudadas é apenas de 3.380 réis. Não obstante, esta análise parece perder sentido quando observados os valores das boticas da Ordem do Carmo, uma vez que estas oscilam entre os 344.420 réis da do Convento de Nossa Senhora da Piedade e os 128.000 réis da do Convento Nossa Senhora dos Remédios.

\section{LITERATURA FARMACÊUTICA}

As primeiras farmacopéias escritas por boticários portugueses na sua língua materna surgiriam apenas no século XVIII. O cônego regrante de Santo Agostinho D. Caetano de Santo António foi autor da Pharmacopea Lusitana, obra pioneira em Portugal, cuja primeira edição data de $1704^{42}$. Outras obras se seguiram, entre as quais o Colectâneo Farmacêutico de António Martins Sodré, dado à estampa em 1735 e uma tradução do Exame de Boticários, de frei Esteban de Villa por José Homem de Andrade, editado no ano de $1736^{43}$.

Formulários, textos de botânica farmacêutica, farmácia química e tratados diversos integravam o espólio das boticas conventuais. Nos inventários consultados apenas em quatro ocasiões foram registados livros pertencentes à boti$\mathrm{ca}^{44}$. Os inventários são bastante parcos em informações, sendo que se em alguns casos é mencionado o título da obra e o autor, noutros apenas é referindo o nome do autor ou, em outras situações, o título incompleto da obra, não existindo nunca referências ao local de edição, nem ao número da mesma.

O boticário do convento de São Domingos de Lisboa tinha ao seu dispor uma biblioteca composta por 41 títulos, divididos entre farmacopéias portu-

42 Sobre esta obra cf. DiAs e PitA (1994), pp. 22-25; PitA, J.R. e PereirA, A.L. (2008), Botica, farmacopéia conventual e farmácia. A Pharmacopea Lusitana de D. Caetano de Santo António (1704). In Actas do III Encontro Cultural de São Cristóvão de Lafões [...], pp. 95-107.

43 DiAS (2007), p. 75. Sobre as diversas farmacopéias que foram dadas à estampa cf. igualmente PITA (1996), pp. 171-229.

44 Em dois dos inventários existe apenas referência ao número de volumes. A botica do convento de Nossa Senhora da Piedade possuía 40 volumes de diversos autores, avaliados em 9.600 réis, enquanto a do convento de São Sebastião era proprietária de 29 livros de farmacêutica. 
guesas e estrangeiras, obras de botânica farmacêutica, livros de matéria médica e dicionários. No que respeita às farmacopéias contabilizámos sete impressas em Portugal e 15 no estrangeiro. Entre as de impressão nacional contavase a Pharmacopea Lusitana de D. Caetano de Santo António ${ }^{45}$, a Pharmacopea Ulyssiponense de João Vigier ${ }^{46}$, o segundo e o terceiro volumes da Pharmacopea Tubalense de Manuel Rodrigues Coelho ${ }^{47}$, a Pharmacopea Dogmatica de frei João de Jesus Maria ${ }^{48}$, a Pharmacopea Lisbonense de Manuel Joaquim Henriques de Paiva ${ }^{49}$, a Pharmacopea Geral para o Reino e Dominios de Portugal, de Francisco Tavares ${ }^{50}$ e a Pharmacopea Chymica, Medica e Cirurgica de António José de Sousa Pinto ${ }^{51}$. Entre as obras estrangeiras destaque para as farmacopéias oficiais como a Pharmacopoeia Londinensis ${ }^{52}$, a Pharmacopoeia Augustana ${ }^{53}$ de Augsburg ou a Pharmacopoeia Edinburgensis ${ }^{54}$. Para além destas, existiam outras de carácter não oficial igualmente da autoria de estrangeiros como são o caso do inglês Thomas Fuller ${ }^{55}$, do austríaco Joseph Jacob Plenck ${ }^{56}$, do francês Antoine

45 AnTÓNIO (D.), C.S. (1704), Pharmacopea Lusitana, Coimbra, Impressão de João Antunes. Tanto nesta nota como nas seguintes apenas será referida a data da primeira edição.

46 Vigier, J. (1716), Pharmacopea Ulyssiponense, Galenica e Chimica, Lisboa, Oficina de Pascoal da Silva.

47 Coelho, M.R. (1735), Pharmacopea Tubalense Chimico-Galenica, primeira e segunda parte, Lisboa, Oficina de António de Sousa da Silva; Coelho, M.R. (1751), Pharmacopea Tubalense Chimico-Galenica, terceira parte, Lisboa, Oficina de José da Silva da Natividade.

48 Maria, (Frei), J.J. (1772), Pharmacopea Dogmatica Medico-Chimica, e TheoricoPratica, Porto, Oficina de António Álvares Ribeiro Guimarães.

49 PaIVA, M.J.H. (1785), Pharmacopea Lisbonense, Lisboa, Oficina de Filipe da Silva e Azevedo.

50 Tavares, F. (1794), Pharmacopea Geral para o Reino, e Dominios de Portugal, Lisboa, Regia Oficina Tipográfica.

51 PINTO, A.J.S. (1805), Pharmacopea Chymica, Medica, e Cirurgica, Lisboa, Impressão Régia.

52 A primeira edição data de 1618, cf. DiAs (2007), p. 121.

53 Não obstante a primeira edição datar de 1564, apenas se tornou oficial, para Augsburg, no ano de 1613, e em todas as províncias austríacas em 1618, cf. DIAS (2007), p. 120.

54 A primeira edição data de 1699, cf. DiAs (2007), p. 121.

55 Fuller, T. (1701), Pharmacopeia Extemporanea, sive Praescriptorum sylloge, In qua remediorum elegantium \& efficacium, paradigmata ad omnes ferè medendi intentiones accomodata candidè proponuntur. Una cum viribus, operandi ratione, \& dosibus annexis, Londres, Imprensa de Sam. Smith \& Benj. Walford.

56 A obra que no inventário aparece designada como farmacopéia cirúrgica de Plenk deverá corresponder a PLENCK, J.J. (1775), Pharmacia chirurgica, seu Doctrina de medicamentis praeparatis accompositis quae ad curandos morbos externos adhiberi solent, Viena de Áustria, Graeffer. 
Baumé $^{57}$ e dos espanhóis Félix Palacios ${ }^{58}$ e Joannes de Loeches ${ }^{59}$.

No que respeita aos livros de botânica realce para uma História das Plantas de Pietro Andrea Mattioli, uma História das Plantas da autoria de João Vigier ${ }^{60}$ e ainda dois volumes da obra As Espécies de Plantas [...] do naturalista e botânico sueco Carl von Linné ${ }^{1}$. De entre os livros estrangeiros de matéria médica evidência para um Dioscórides Anazarbeo por Legeme ${ }^{62} \mathrm{e}$ para o Corpus Pharmaceutico-Chymico-Medicum Universale da autoria de Johann Helfrich Jüngken ${ }^{63}$. Sobre a mesma temática, mas da autoria de nacionais, contava-se a Polyanthea Medicinal de João Curvo de Semedo ${ }^{64}$, a Historiologia Médica de Rodrigues de Abreu ${ }^{65}$, a obra Illustração Medica [...] de Duarte Rebelo Saldanha ${ }^{66}$ e uma Matéria Médica [...] de António José de Sousa Pinto ${ }^{67}$. Por último, destaque para a existência de um pequeno

57 Baume, A. (1762), Elémens de Pharmacie theorique et pratique, avec une Table des Vertus \& Doses des Médicamens, Paris, Veuve Damonneville \& Musier fils.

58 Palacios, F. (1706), Palestra Pharmaceutica Chimico-Galenica, Madrid, García Infançon.

59 Loeches, J. (1719), Tyrocinium Pharmaceuticum Theorico-Practicum GalenoChymicum, Madrid, Martinez.

60 Vigier, J. (1718), Historia das Plantas da Europa, e das mais uzadas que vem de Asia, de Affrica, \& da America onde se ve suas figuras, seus nomes, em que tempo florecem e o lugar onde nacem, com hum breve discurso de suas qualidades e virtudes especificas, Lion, Oficina de Anisson, Posuel et Rigaud.

61 LINNÉ, C. (1753), Species plantarum, exhibentes plantas rite cognitas ad genera relatas, Holmiae, Impressor Laurentii Salvii.

62 Dioscórides foi impresso pela primeira vez em 1478 por P. d'Abano. No ano de 1499, foi dada à estampa a sua primeira edição em Grego por Roscius. A obra conheceu grande número de edições e traduções. A principal tradução ibérica ficou a dever-se a Andrés de Laguna e foi impressa em Antuérpia no ano de 1555. Pensamos que a edição existente no convento de São Domingos que o escrivão atribui a um Legeme seja, na verdade, de Laguna.

63 JÜngken, J.H. (1697), Corpus Pharmaceutico-Chymico-Medicum Universale, Frankfurt, ad Moenum, sumptibus Friderici Knochii.

64 Semedo, J.C. (1697), Polyanthea Medicinal. Noticias Galenicas e Chymicas, repartidas em tres tratados, Lisboa, Miguel Deslandes.

65 ABREU, J.R. (1733), Historiologia Medica, fundada e estabelecida nos principios de George Ernesto Stahl, e ajustada ao uso pratico deste paiz, Lisboa Ocidental, Oficina da Música.

66 SAldanHA, D.R. (1761-1762), Illustração Medica, Ethico-politica, Historicosistematica, Sceptico-ecletica, Fizico-analitica, e Theorico-pratica, ou Reflexão critica ás Consideraçoens Medicas, sobre o methodo de conhecer, curar, e prezervar as epidemias, ou febres malignas, podres, pestilenciaes, contagiosas, Lisboa, Régia Oficina Silviana.

67 PINTO, A.J.S. (1813), Matéria médica distribuida em classes e ordens segundo seus efeitos. Adicionada com as taboas da Matéria Medica e de um Diccionário Nosologico ou 
dicionário de francês que auxiliaria o boticário na leitura das obras escritas naquele idioma.

No convento dos religiosos Carmelitas Descalços de Tavira foram inventariados 13 títulos. Existiam três farmacopéias nacionais a saber a Pharmacopea Tubalense, a Pharmacopea Lisbonense e a Pharmacopea Geral para o Reino e Dominios de Portugal. Para além destas foi registada uma farmácia de Leal, que deverá corresponder à obra Instituições ou Elementos de Farmácia $[\ldots]$ de José Francisco Leal ${ }^{68}$. De entre as obras estrangeiras destaque para a Pharmacopoea Generalis de Jacob Reinbold Spielmann ${ }^{69}$. No que toca aos livros de farmácia química realce para uma química de Seabra ${ }^{70}$. No ramo da botânica o inventário deu conta de uma obra da autoria de Félix de Avelar de Brotero a qual apenas foi catalogada com o título de Elementos e que deverá corresponder ao Compendio de Botanica ou Noçoens Elementares [...] $]^{71}$. O inventário compreendia ainda um Tratado [...] das Águas das Caldas da Rainha, de José Nunes Gago ${ }^{72}$.

A análise destas duas bibliotecas farmacêuticas não permite tirar grandes ilações sobre as obras mais difundidas e utilizadas nestes espaços. Para tal seria necessário o estudo de outros catálogos de livros pertencentes a estas boticas conventuais. Ainda assim os dados recolhidos possibilitam a identificação de autores e obras que se repetem nas duas boticas e como tal seriam usuais em Portugal. Desta forma, para além das três farmacopéias portuguesas enunciadas em Tavira que existiam também na botica de São Domingos, temos as farmacopéias dos ingleses Thomas Fuller e William Lewis ${ }^{73}$. O pri-

Nomenclaturas Synonomica das molestias, symptomas vicios o affecções da Natureza. Para uso dos Estudantes e Praticos Modernos, Lisboa, Impressão Régia.

68 LEAL, J.F. (1792), Instituiçoes ou Elementos de Farmácia Extrahidos dos de Baumé, e reduzidos a novo methodo, Lisboa, Oficina de António Gomes. Sobre esta obra cf. PITA, J.R. (1993), O conceito de farmácia nas 'Instituiçoes ou Elementos de Farmácia' de José Francisco Leal, Medicamento, História e Sociedade, Nova Série, ano I, n. ${ }^{\circ}$ 2, Lisboa, pp. 1-5.

69 Spielmann, J.R. (1783), Pharmacopoea Generalis, Argentorati, J.-G. Treuttel.

70 Teles, V.C.S.S. (1788-1790), Elementos de Chimica, Coimbra, Real Oficina da Universidade.

71 Brotero, F.A. (1788), Compendio de Botanica ou Noçoens Elementares desta Sciencia segundo os melhores escritores modernos, expostas na lingua portugueza, Paris, [s.n.].

72 Gago, J.N. (1779), Tratado Phizico-Chimico-Medico das Aguas das Caldas da Rainha, Lisboa, Tipografia Rollandiana.

73 A farmacopéia de Lewis que se repete nos dois catálogos deverá corresponder a LEWIS, W. (1744), Pharmacopoeia Reformata. Essay for a reformation of the London Pharmacopoeia by a se of remarks on the draught for a new one, and on the brief account of the proceedings of the committee appointed by the college of physicians, to thoroughly reform their 
meiro era bastante popular em toda a Península Ibérica. Em Portugal sabemos que também se encontrava presente nos mosteiros de São Martinho de Tibães ${ }^{74}$, de Santa Maria de Landim ${ }^{75}$ e no de Grijó ${ }^{76}$. Em Espanha, concretamente na região da Galiza, existiam exemplares da sua farmacopéia na pequena biblioteca da botica do mosteiro de Oseira e na do mosteiro de Celanova ${ }^{77}$.

Se tivermos em conta as datas das primeiras edições das obras presentes nos catálogos verificamos que a maioria das obras (33\%), no caso de São Domingos de Lisboa, foi impressa entre 1701 e 1750, e no caso do convento de Tavira (46\%) foi editada no período compreendido entre 1751 e 1800 . A obra mais antiga pertencia à botica de São Domingos e era da autoria de Pietro Andrea Mattioli que escreveu no século XVI, já o convento de Tavira não possuía obras anteriores a 1701, o que poderá estar relacionado com a antiguidade das boticas. O gráfico 1 demonstra que nas duas bibliotecas farmacêuticas a maioria das obras (32\%) foi impressa entre 1701 e 1750, seguindose o período de 1751 a $1800(26 \%)$. A percentagem das obras impressas no século XIX ficou muito atrás das editadas em setecentos - apenas 6\%. Ribeiro Sanches mencionou existirem em Portugal «bibliothecas inteiras das nossas Pharmacopeas como são a dos P.P. Vicentes, a Setubalense, e outras muitas de que me esqueci, semelhantes a Viennense, a Parisiense e a Madritense; que servem hoje de monumentos da ignorancia da chemica racional, e da Materia Medica ${ }^{78}$. A literatura existente parece de facto e numa primeira análise algo antiga, contudo é necessário ter em conta a percentagem de obras $(19 \%)$ que não nos foi possível identificar e que poderia alterar significativamente os resultados. Por outro lado, há que ter em consideração o facto de desconhecermos a edição das obras existentes, tal facto reveste-se da maior

book, London, R. Willock. A obra anónima tinha, no final da dedicatória, as iniciais M. S. o que levantou a hipótese do seu autor ser o médico judeu Meyer Loew Schomberg. Não obstante, já na centúria de setecentos a sua autoria era atribuída a William Lewis. A comprová-lo está um catálogo de uma biblioteca pertencente a Henry Pemberton, datado de 1776, que refere um livro sob a designação de Lewis's Pharmacopoeia Reformata 1744, cf. EARLES, M. (1976), The author of the Pharmacopoeia Reformata 1744, Medical History, 20 (1), Londres, pp. 70-75.

74 MATA (1992) p. não numerada.

75 MARQUES (2008), p. 42.

76 Silva (1972), pp. 18 e 30.

77 SÁ Bravo, H. (1983), Boticas Monacales y Medicina Naturalista en Galicia, Madrid, Editorial Everest, pp. 71-72 e 88.

78 SANChES, A.N.R. (1966), Obras, vol. 2, Coimbra, Biblioteca Geral da Universidade de Coimbra, p. 67. 
importância pois como é sabido algumas sofriam modificações consideráveis de edição para edição. Por fim ambas as bibliotecas parecem actualizadas pelo menos no que respeita às farmacopéias portuguesas, uma vez que possuíam a maioria das obras que foi sendo dada à estampa.

GRÁFICO 1. DATAS DA PRIMEIRA EDIÇÃO DAS OBRAS PERTENCENTES ÀS BOTICAS DOS CONVENTOS DE SÃO DOMINGOS DE LISBOA E CONVENTO DOS CARMELITAS DESCALÇOS DE TAVIRA

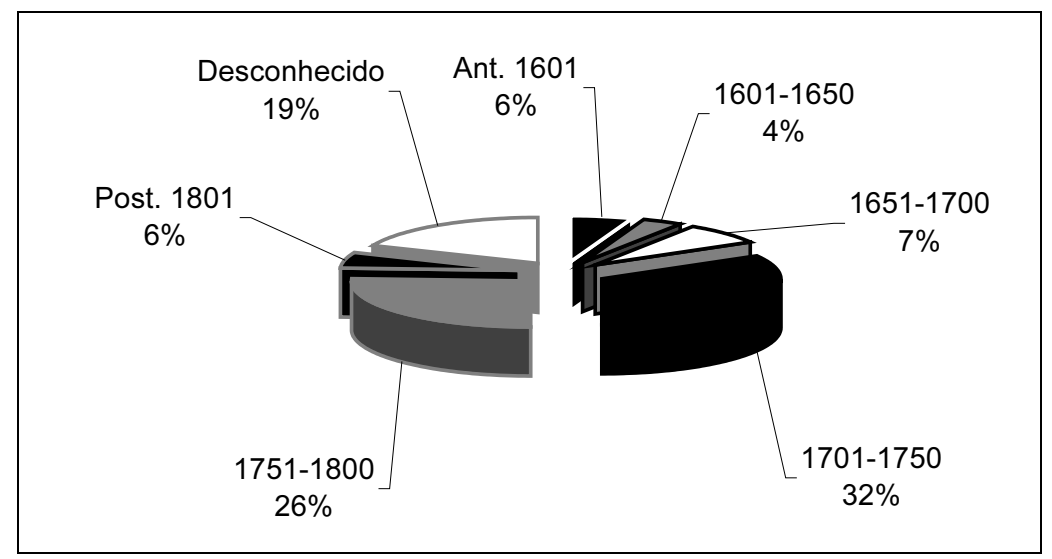

Fonte: Lisboa, A.N.T.T., MNEJ, caixa 184, maço 229; caixa 225, maço 280.

\section{RENDIMENTOS}

A grande actividade das boticas conventuais pode ser comprovada pelas dívidas de que as mesmas eram credoras. A título de exemplo veja-se o caso da botica do Convento dos Carmelitas Descalços de Tavira, à qual 73 pessoas deviam um total de 478.080 réis. De entre esses indivíduos destaque para os majores Sebastião Fernandes Estancio e André Vás Guerreiro, e para uma dona Mónica Maria Pau cujas dívidas perfaziam os 95.200, 65.900 e 79.700 réis, respectivamente. Permanece desconhecido o ofício da maioria das pessoas que recorriam aos serviços daquela botica pois somente em 29 casos foi registada a sua profissão. De entre estes, destaque para os indivíduos ligados ao sector militar: quatro majores, quatro capitães, dois sargentos e um coronel. De entre os indivíduos pertencentes ao sector artesão contavam-se quatro sapateiros, dois carpinteiros, um alfaiate, um pedreiro e um ferreiro. De entre 
os devedores do sector comercial foram apontados quatro mercantes, enquanto que do sector administrativo haviam contraído dívidas um guarda da alfândega, um tabelião e um meirinho. Além destes foram ainda registados um almocreve e os herdeiros de um doutor ${ }^{79}$.

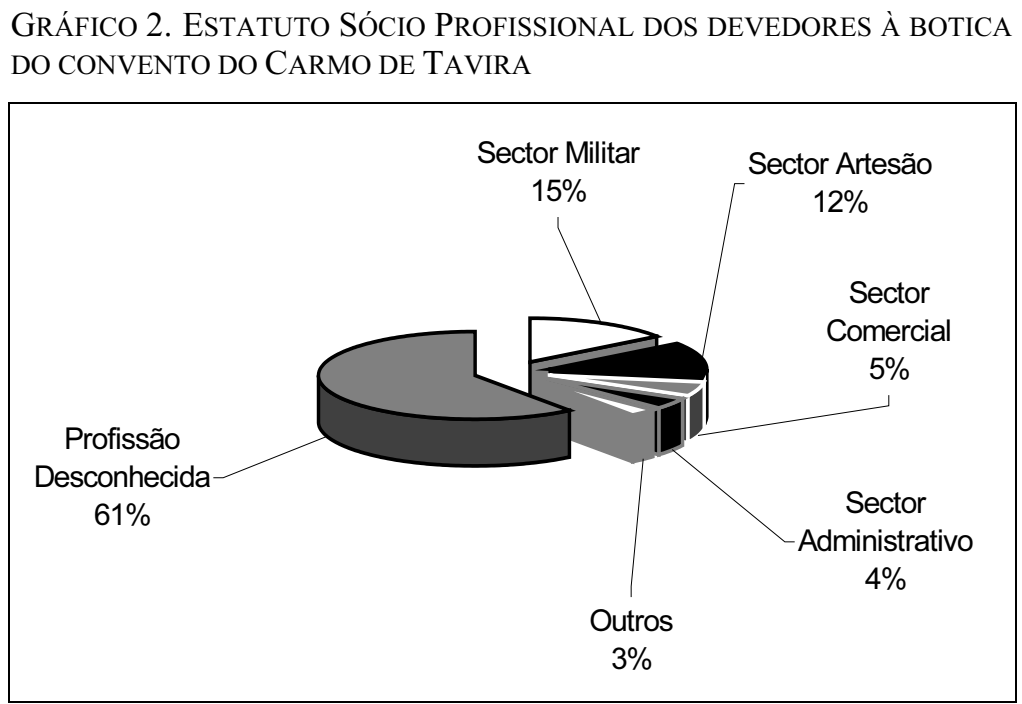

Fonte: Lisboa, A.N.T.T., MNEJ, caixa 184, maço 229.

Ao convento de São Domingos de Lisboa eram devidos de receitas e partidos 700.000 réis $^{80}$. Frei Manuel de Santa Catarina, boticário do mosteiro beneditino de Paço de Sousa, declarou que se devia em receitas da botica, antigas e modernas, 351.120 réis, cuja quantia declarou não poder arrecadar por serem a maior parte delas de pobres ${ }^{81}$.

No que diz respeito aos rendimentos das boticas conventuais, o convento de São Domingos de Lisboa recebia 716.400 réis, que correspondia somente a $3.7 \%$ de um total de 19249.282 réis de rendas ${ }^{82}$. A botica São João da Pesqueira rendia anualmente perto de 200.000 réis. Os avaliadores da botica de

\footnotetext{
79 Lisboa, A.N.T.T., MNEJ, caixa 184, maço 229.

80 Lisboa, A.N.T.T., MNEJ, caixa 225, maço 280.

81 Lisboa, A.N.T.T., MNEJ, caixa 187, maço 233, n. ${ }^{\circ}$ 1-3.

82 Lisboa, A.N.T.T., MNEJ, caixa 225, maço 280.
} 
Nossa Senhora da Piedade, em Cascais, referiram que a mesma poderia render diariamente 480 réis o que importaria no decurso de um ano a quantia de 175.200 réis $^{83}$, já a renda da botica do convento de Tavira importava os 67.600 réis $^{84}$.

\section{CONCLUSÕES}

Num período em que os boticários leigos ao invés de investirem na sua área profissional procuravam antes outras áreas, nomeadamente a aquisição de bens de raiz, empréstimos a juro e entrada dos filhos no clero, visando a sua ascensão social, as farmácias conventuais assumiram uma enorme projeção. Estas não se limitavam a servir os internos, abastecendo em muitos casos toda uma localidade. Este facto, aliado à sua importância económica, gerou contestação tendo chegado a ser equacionada uma forma de acabar com tais espaços.

A investigação possibilitou conhecer e divulgar o recheio de algumas boticas conventuais. Não obstante as diferenças de valor entre as farmácias estudadas, todas as casas religiosas possuíam na sua botica a maioria dos utensílios necessários à prática farmacêutica. Para além das alfaias alguns dos inventários deram conta que alguns destes espaços possuíam laboratório e casa de destilação.

A análise das bibliotecas das boticas permitiu verificar que estas se encontravam bem munidas, não obstante parecerem, numa primeira análise, desactualizadas. Possibilitou igualmente identificar autores cujas obras se encontravam amplamente difundidas nestes espaços como, por exemplo, a Pharmacopoeia de Thomas Fuller.

Alguns dos inventários parecem sugerir que o período áureo das boticas conventuais tinha terminado, o que parece ser comprovado pela falta de instrumentos essenciais, tais como balanças, e pela escassez de drogas. De facto, estava para breve o final destas farmácias. Poucos anos volvidos, em 30 de Maio de 1834, eram extintas as ordens religiosas masculinas em Portugal e com elas as boticas conventuais.

83 Lisboa, A.N.T.T., MNEJ, caixa 231, maço 285.

84 Lisboa, A.N.T.T., MNEJ, caixa 184, maço 229. 
Quadro 1. Convento de SÃo Francisco de SÃo Jõ̃o da PESQUeIRA

\begin{tabular}{|c|c|c|c|}
\hline Objetos & Quantidade & Preço (réis) & Observações \\
\hline Vasos de pó de pedra & 50 & 30.000 & \\
\hline $\begin{array}{l}\text { Vasos de louça com tampa de lata } \\
\text { dourada }\end{array}$ & & 20.000 & $\begin{array}{l}\text { Quantidade não } \\
\text { especificada }\end{array}$ \\
\hline $\begin{array}{l}\text { Vasos de louça mesclada de azul e } \\
\text { branco com tampas de lata }\end{array}$ & 60 & 18.000 & \\
\hline Vasos de pó de pedra & 13 & 4.600 & Pequenos \\
\hline Vasos de vidro & 54 & 27.000 & Grandes \\
\hline Garrafas de cristal & 25 & 12.000 & \\
\hline $\begin{array}{l}\text { Açucareiros de vidro com tampa de } \\
\text { lata dourada }\end{array}$ & 41 & 4.100 & \\
\hline Vidros com rolha do mesmo & 173 & 27.680 & Pequenos \\
\hline $\begin{array}{l}\text { Almofarizes de vidro com mãos do } \\
\text { mesmo material }\end{array}$ & 2 & 960 & \\
\hline Funis de vidro & 2 & 600 & \\
\hline Funil de metal amarelo & 1 & 1.200 & \\
\hline Funis de lata & 4 & 200 & \\
\hline Almofarizes de bronze & 2 & 3.600 & Pequenos \\
\hline $\begin{array}{l}\text { Almofariz de chumbo com mão de } \\
\text { marfim }\end{array}$ & 1 & 1.450 & \\
\hline $\begin{array}{l}\text { Almofarizes de marfim com mão de } \\
\text { madeira }\end{array}$ & 2 & 1.200 & \\
\hline $\begin{array}{l}\text { Almofarizes de ferro com mão do } \\
\text { mesmo material }\end{array}$ & 2 & 8.000 & Grande \\
\hline Almofarizes de mármore & 3 & 4.800 & $\begin{array}{l}\text { Todos os taman- } \\
\text { hos }\end{array}$ \\
\hline Caceta de metal amarelo & 1 & 3.200 & \\
\hline Medidas de metal amarelo & 2 & 1.800 & De libra \\
\hline Medidas de metal amarelo & 3 & 1.400 & De meia libra \\
\hline Medidas & $1 /$ cada & 400 & $\begin{array}{l}\text { De onça e meia } \\
\text { onça }\end{array}$ \\
\hline Alambique de cobre & 1 & 4.800 & \\
\hline Tachos de latão amarelo & 5 & 8.200 & $\begin{array}{l}\text { Diversos taman- } \\
\text { hos }\end{array}$ \\
\hline Alambiques de lata & 2 & 3.200 & \\
\hline Panelas de lata & 11 & 2.320 & $\begin{array}{l}\text { Diversos taman- } \\
\text { hos }\end{array}$ \\
\hline
\end{tabular}




\begin{tabular}{|l|c|c|l|}
\hline \multicolumn{1}{|c|}{ Objetos } & Quantidade & Preço (réis) & Observações \\
\hline Tamises & 5 & 2.400 & \\
\hline Espátulas de ferro e metal & 10 & 2.400 & \\
\hline Sedaços & 2 & 1.400 & \\
\hline Prensa de madeira & 1 & 4.800 & \\
\hline Mesa de laboratório & 1 & 1.600 & \\
\hline Caneco para água & 1 & 500 & \\
\hline $\begin{array}{l}\text { Relógio de parede com caixa pintada } \\
\text { e dourada }\end{array}$ & 1 & 40.000 & \\
\hline Balanças & 4 & 4.740 & $\begin{array}{l}\text { Diversos taman- } \\
\text { hos }\end{array}$ \\
\hline Marco & 1 & 1.400 & De arrátel \\
\hline Drogas na botica e armazém & 1 & 300.000 & $\begin{array}{l}\text { Quantidade não } \\
\text { especificada }\end{array}$ \\
\hline Pintura da botica & 96.000 & \\
\hline
\end{tabular}

Fonte: Lisboa, A.N.T.T., MNEJ, caixa 184, maço 229.

Quadro 2. CONVENTO dos Religiosos CARMElitas Descalços DE TAVIRA

\begin{tabular}{|c|c|c|c|}
\hline Objetos & Quantidade & Preço (réis) & Observações \\
\hline Panelas & 21 & 10.500 & Grandes \\
\hline Panelas & 19 & 5.700 & Medianas \\
\hline Panelas & 20 & 3.500 & Pequenas \\
\hline Vasos de unguentos & 20 & 4.000 & \\
\hline Vasos de unguentos & 44 & 4.400 & Pequenos \\
\hline $\begin{array}{l}\text { Garrafas de vidro com rolha do } \\
\text { mesmo material }\end{array}$ & 55 & 13.200 & Oitavadas \\
\hline Garrafas de vidro fino sem rolha & 43 & 4.300 & \\
\hline $\begin{array}{l}\text { Frascos de vidro com rolha do mes- } \\
\text { mo material }\end{array}$ & 33 & 5.280 & Grandes \\
\hline Frascos de vidro fino sem rolha & 153 & 15.300 & \\
\hline Alambique de cobre & 1 & 3.200 & Catorze canadas \\
\hline Alambique de lata & 1 & 600 & $\begin{array}{l}\text { Dezasseis cana- } \\
\text { das }\end{array}$ \\
\hline Alambique de lata & 1 & 300 & Quatro canadas \\
\hline Alambique de lata & 1 & 300 & $\begin{array}{l}\text { Seis canadas, } \\
\text { muito usado }\end{array}$ \\
\hline
\end{tabular}




\begin{tabular}{|c|c|c|c|}
\hline Objetos & Quantidade & Preço (réis) & Observações \\
\hline $\begin{array}{l}\text { Almofariz de bronze com mão de } \\
\text { ferro }\end{array}$ & 1 & 3.200 & Grande \\
\hline $\begin{array}{l}\text { Almofariz de bronze com mão do } \\
\text { mesmo material }\end{array}$ & 2 & 1.200 & Pequeno \\
\hline $\begin{array}{l}\text { Almofariz de chumbo, com mão do } \\
\text { mesmo material }\end{array}$ & 1 & 480 & \\
\hline Gral de marfim com mão quebrada & 1 & 600 & \\
\hline $\begin{array}{l}\text { Gral de vidro com mão do mesmo } \\
\text { material }\end{array}$ & 1 & 120 & \\
\hline Gral de pedra com mão de madeira & 1 & 1.200 & Grande \\
\hline Grais com mão de madeira & 4 & 1.600 & Mediano \\
\hline Funis de estanho & 2 & 300 & \\
\hline Medida de estanho & 1 & 100 & De libra \\
\hline Medida de estanho & 1 & 60 & De meia libra \\
\hline Medida de estanho & 1 & 40 & De onça \\
\hline Espátula de vidro & 1 & 60 & \\
\hline Espátulas de marfim & 2 & 800 & \\
\hline Espátulas de ferro & 6 & 380 & \\
\hline Faca de marfim & 1 & 480 & \\
\hline Panelas de lata & 4 & 480 & Em bom uso \\
\hline Prensa de parafuso de ferro & 1 & 6.400 & \\
\hline Balança & 1 & 1.600 & $\begin{array}{l}\text { De arrátel com } \\
\text { um marco de } \\
\text { dois arráteis, } \\
\text { usada }\end{array}$ \\
\hline Balanças & 2 & 1.600 & $\begin{array}{l}\text { De quarta, com } \\
\text { dois marcos de } \\
\text { quarta, em uso }\end{array}$ \\
\hline Balança de grãos & 1 & 480 & \\
\hline Peneiras & 4 & 800 & \\
\hline Vasos & 5 & 1.600 & $\begin{array}{l}\text { Diversos taman- } \\
\text { hos }\end{array}$ \\
\hline Tesouras & 2 & 600 & $\begin{array}{l}\text { Uma maior, } \\
\text { outra menor }\end{array}$ \\
\hline Sedaços & 2 & 160 & \\
\hline Peneira fina & 1 & 100 & \\
\hline Candeeiro de arame amarelo & 1 & 300 & Muito usado \\
\hline
\end{tabular}




\begin{tabular}{|l|c|c|l|}
\hline \multicolumn{1}{|c|}{ Objetos } & Quantidade & Preço (réis) & Observações \\
\hline Escumadeiras & 2 & 80 & \\
\hline Livros Tubalenses & 2 & 800 & \\
\hline Farmacopéia de Lewis & 3 & 2.000 & \\
\hline Spielmann & 1 & 800 & \\
\hline Fuller & 1 & 600 & \\
\hline Farmacopéia de Valy & 1 & 160 & \\
\hline Farmacopéia Lisbonense & 1 & 200 & \\
\hline Farmácia de Leal & 1 & 200 & \\
\hline Tratado de Água das Caldas & 1 & 400 & \\
\hline Filosofia Química de Froque & 1 & 480 & \\
\hline Vigeres [João Vigier] & 2 & 600 & \\
\hline Elementos de Brotero & 2 & 1.600 & \\
\hline Química de Seabra & 1 & 1.200 & Em bom uso \\
\hline Geral do Reino & 2 & 1.200 & Em bom uso \\
\hline $\begin{array}{l}\text { Armação da Botica e administrado- } \\
\text { res de madeira pintada }\end{array}$ & 1 & 19.200 & Em bom uso \\
\hline \\
Drogas e composições & & 160.000 & $\begin{array}{l}\text { Quantidade não } \\
\text { especificada }\end{array}$ \\
\hline
\end{tabular}

Fonte: Lisboa, A.N.T.T., MNEJ, caixa 184, maço 229.

QuAdro 3. CONVENTO DE CORPUS CHRISTI (LISBOA)

\begin{tabular}{|l|c|c|l|}
\hline \multicolumn{1}{|c|}{ Objetos } & Quantidade & Preço (réis) & \multicolumn{1}{|c|}{ Observações } \\
\hline Armação da botica & 1 & 60.000 & \\
\hline Alambiques de cobre & 2 & 7.680 & $\begin{array}{l}\text { Peso: arroba e } \\
\text { meia }\end{array}$ \\
\hline Tachos velhos de latão & 5 & 1.480 & Peso: 14 arráteis \\
\hline Almofarizes de bronze & 2 & 7.200 & Peso: 60 arráteis \\
\hline Candeeiro de latão & 1 & 240 & $\begin{array}{l}\text { Peso: dois arrá- } \\
\text { teis }\end{array}$ \\
\hline Vidros sorteados & 238 & 19.040 & $\begin{array}{l}\text { Diversos taman- } \\
\text { hos }\end{array}$ \\
\hline Garrafões sorteados & 7 & 7.000 & \\
\hline Frascos pretos & 7 & 560 & \\
\hline Vasos & 16 & 400 & Pequenos
\end{tabular}


PARA O ESTUDO DA SAÚDE CONVENTUAL NO INÍCIO DO SÉCULO XIX: AS BOTICAS

\begin{tabular}{|l|c|c|l|}
\hline \multicolumn{1}{|c|}{ Objetos } & Quantidade & Preço (réis) & Observações \\
\hline Retortas & 2 & 960 & \\
\hline Panelas de barro vidradas & 57 & 9.120 & \\
\hline Vasos de barro azuis & 100 & 10.000 & \\
\hline Vasos de barro & 80 & 6.400 & \\
\hline Vasos brancos & 20 & 400 & \\
\hline Pedras de preparos & 3 & 1.440 & \\
\hline Drogas na botica e armazém & & & $\begin{array}{l}\text { Quantidade e } \\
\text { valor não } \\
\text { especificado }\end{array}$ \\
\hline
\end{tabular}

Fonte: Lisboa, A.N.T.T., MNEJ, caixa 184, maço 229.

QuAdro 4. CONVENTO de Nossa SENHORA dos REMÉdios (LiSBOA)

\begin{tabular}{|l|c|c|l|}
\hline \multicolumn{1}{|c|}{ Objetos } & Quantidade & Preço (réis) & \multicolumn{1}{|c|}{ Observações } \\
\hline Armação de madeira pintada & 1 & 19.200 & Usada \\
\hline Armário & 1 & 960 & Usado \\
\hline Urna & 1 & 1.000 & \\
\hline Bancos & 3 & 600 & Velhos \\
\hline Banca & 1 & 360 & Velha \\
\hline Vasos de loiça da fábrica & 250 & 40.000 & $\begin{array}{l}\text { Diversos taman- } \\
\text { hos }\end{array}$ \\
\hline Vasos de loiça & 130 & 3.420 & Sortidos \\
\hline Vidros & 180 & 18.000 & Grandes \\
\hline Vidros & 130 & 6.500 & Pequenos \\
\hline Vidros & 220 & 8.800 & Sortidos \\
\hline Bilhas de cobre & 2 & 2.240 & Peso: 14 arráteis \\
\hline $\begin{array}{l}\text { Chocolateiras, um tacho e um foga- } \\
\text { reiro tudo de cobre }\end{array}$ & 4 & 4.160 & Peso: 26 arráteis \\
\hline $\begin{array}{l}\text { Alambique, fogareiro e tacho tudo } \\
\text { de cobre }\end{array}$ & $1 /$ cada & 11.520 & Peso: 72 arráteis \\
\hline Almofariz de cobre & 1 & 6.400 & Grande \\
\hline Alambique de cobre & 1 & 5.440 & Peso: 34 arráteis \\
\hline
\end{tabular}

Fonte: Lisboa, A.N.T.T., MNEJ, caixa 184, maço 229. 
QuAdro 5. MOSTEIRo SANTO ANDRÉ DE RENDUFE

\begin{tabular}{|c|c|c|c|}
\hline Objetos & Quantidade & Preço (réis) & Observações \\
\hline $\begin{array}{l}\text { Redomas de vidro com rolhas do } \\
\text { mesmo material }\end{array}$ & 18 & 4.320 & Sãs \\
\hline $\begin{array}{l}\text { Redomas de vidro com rolha do } \\
\text { mesmo material }\end{array}$ & 21 & 1.050 & $\begin{array}{l}\text { Usadas e senti- } \\
\text { das }\end{array}$ \\
\hline $\begin{array}{l}\text { Redomas de vidro com rolha de } \\
\text { cortiça }\end{array}$ & 14 & 6.720 & \\
\hline Redomas & 2 & 120 & Já estaladas \\
\hline Vidros & 126 & 7.560 & Pequenos \\
\hline Garrafas pretas & 8 & 480 & $\begin{array}{l}\text { De quartilho e } \\
\text { meio }\end{array}$ \\
\hline Funis de vidro & 2 & 160 & \\
\hline Copos de vidro & 2 & 600 & \\
\hline Latinhas de folha & 12 & 600 & \\
\hline Lata & 1 & 200 & Grande, usada \\
\hline Funil de folha de lata & 1 & 40 & \\
\hline Funil de latão & 1 & 200 & \\
\hline Medidas de latão e de folha & 1 de cada & 600 & De libra \\
\hline Medidas de latão & 2 & 250 & \\
\hline Marco & 1 & 1.500 & Peso: arrátel \\
\hline Marco & 1 & 750 & Peso: meio arrátel \\
\hline Balanças & 2 & 1.000 & Grandes \\
\hline Balança & 1 & 500 & Pequena \\
\hline Almofariz de bronze & 1 & 3.000 & Pequeno \\
\hline Almofariz de pedra & 2 & 800 & \\
\hline Almofariz de ferro & 1 & 600 & Grande, rachado \\
\hline Graal com vários pezinhos & 1 & 160 & \\
\hline Alambiques de folha & 2 & 600 & Velhos \\
\hline Tachos de cobre & 5 & 1.500 & Velhos \\
\hline Espátulas de ferro & 3 & 90 & \\
\hline Escumadeira de latão & 1 & 80 & Velha \\
\hline Ralador & 1 & 120 & \\
\hline Candeeiro & 1 & 400 & Pequeno \\
\hline Peneiras & 4 & 400 & Velhas \\
\hline Sedaços & 3 & 240 & Usados \\
\hline
\end{tabular}


PARA O ESTUDO DA SAÚDE CONVENTUAL NO INÍCIO DO SÉCULO XIX: AS BOTICAS

\begin{tabular}{|c|c|c|c|}
\hline Objetos & Quantidade & Preço (réis) & Observações \\
\hline Panelas de folha & 4 & 360 & \\
\hline \multicolumn{4}{|l|}{ Móveis de pau } \\
\hline Estantes, mostrador e gavetas & & 24.000 & \\
\hline Contador de gavetas de madeira & 1 & 600 & $\begin{array}{l}\text { Usado e muito } \\
\text { velho }\end{array}$ \\
\hline Mesa velha de castanho feita à antiga & 1 & 240 & Muito velha \\
\hline \multicolumn{4}{|l|}{ Louças } \\
\hline $\begin{array}{l}\text { Vasos de barro vidrados, com tampa } \\
\text { do mesmo material e pintados a azul }\end{array}$ & 56 & 16.800 & $\begin{array}{l}\text { Largos e em } \\
\text { bom uso }\end{array}$ \\
\hline Vasos & 40 & 6.400 & Altos \\
\hline Púcaros de barro grosso & 21 & 300 & $\begin{array}{l}\text { Diversos taman- } \\
\text { hos }\end{array}$ \\
\hline Alguidares & 3 & 90 & \\
\hline Pires finos & 2 & 60 & Usados \\
\hline Cântaro grosso & 1 & 50 & \\
\hline Copos de barro grosso branco & 4 & 240 & \\
\hline \multicolumn{4}{|l|}{ Roupas } \\
\hline Coadores de lã & 5 & 540 & Usados \\
\hline $\begin{array}{l}\text { Coador de linho para coar os remé- } \\
\text { dios }\end{array}$ & 1 & 60 & Usados \\
\hline
\end{tabular}

Fonte: Lisboa, A.N.T.T., MNEJ, caixa 229, maço 283.

Quadro 6. Mosteiro Beneditino de PAÇO DE Sousa

\begin{tabular}{|l|c|c|l|}
\hline \multicolumn{1}{|c|}{ Objetos } & Quantidade & Preço (réis) & \multicolumn{1}{|c|}{ Observações } \\
\hline Vasos de barro e panelas & 152 & 4.560 & $\begin{array}{l}\text { Alguns quebra- } \\
\text { dos }\end{array}$ \\
\hline Redomas de vidro & 50 & 10.000 & Antigas \\
\hline Açucareiros de vidro & 94 & 1.880 & Antigos \\
\hline Vidros & 104 & 5.200 & $\begin{array}{l}\text { Diversos taman- } \\
\text { hos }\end{array}$ \\
\hline Panelas de vidro & 6 & 480 & Antigas \\
\hline Garrafas de vidro preto & 53 & 1.060 & Antigas \\
\hline Almofariz de bronze & 3 & 6.240 & $\begin{array}{l}\text { Grandes e pe- } \\
\text { quenos }\end{array}$ \\
\hline Almofariz de pedra mármore & 2 & 900 &
\end{tabular}




\begin{tabular}{|l|c|c|l|}
\hline \multicolumn{1}{|c|}{ Objetos } & Quantidade & Preço (réis) & \multicolumn{1}{|c|}{ Observações } \\
\hline Alambiques de cobre & 2 & 5.760 & \\
\hline Tachos de latão & 6 & 7.680 & $\begin{array}{l}\text { Diversos taman- } \\
\text { hos }\end{array}$ \\
\hline Funis & 2 & 120 & \\
\hline Tamises & 4 & 480 & \\
\hline Balanças & 3 & 800 & $\begin{array}{l}\text { Diversos taman- } \\
\text { hos }\end{array}$ \\
\hline Marco & 1 & 600 & $\begin{array}{l}\text { Peso: dois arrá- } \\
\text { teis }\end{array}$ \\
\hline Medida de cobre & 1 & 240 & $\begin{array}{l}\text { Quantidade não } \\
\text { especificada }\end{array}$ \\
\hline Drogas & & 35.000 &
\end{tabular}

Fonte: Lisboa, A.N.T.T., MNEJ, caixa 187, maço 233, n. ${ }^{\circ} 1-3$.

QuAdro 7. CONVENTO DE SÃo Domingos (LisBoA)

\begin{tabular}{|l|c|c|l|}
\hline \multicolumn{1}{|c|}{ Objetos } & Quantidade & Preço (réis) & \multicolumn{1}{|c|}{ Observações } \\
\hline Mesas de pau & 2 & $\begin{array}{c}\text { Não tem } \\
\text { quantia }\end{array}$ & \\
\hline Tamboretes & 6 & $\begin{array}{c}\text { Não tem } \\
\text { quantia }\end{array}$ & Muito usados \\
\hline Banco de encosto & 1 & 360 & Muito usado \\
\hline Escadas de mão & 2 & 600 & \\
\hline Panelas de barro vidradas & 100 & 5.000 & Ordinárias \\
\hline Potes de barro & 196 & 11.580 & $\begin{array}{l}\text { Ordinário, sorti- } \\
\text { dos }\end{array}$ \\
\hline Redomas de vidro & 153 & 30.000 & Sortidas \\
\hline Potes de vidro & 185 & 11.100 & Sortidas \\
\hline Vidros com rolhas do mesmo material & 149 & 8.940 & 400 \\
\hline Frascos lapidados & 4 & 180 & Muito usado \\
\hline Frascos de vidro preto & 6 & 8.400 & $\begin{array}{l}\text { Diferentes ta- } \\
\text { manhos }\end{array}$ \\
\hline Garrafões pretos & 22 & $\begin{array}{l}\text { Sem valer nen- } \\
\text { hum }\end{array}$ \\
\hline Talhas de barro enterradas em pedra & 10 & $\begin{array}{l}\text { Quantidade não } \\
\text { especificada }\end{array}$ \\
\hline Medicamentos capazes de servir & & 72.000 & \\
\hline
\end{tabular}


PARA O ESTUDO DA SAÚDE CONVENTUAL NO INÍCIO DO SÉCULO XIX: AS BOTICAS

\begin{tabular}{|l|c|c|l|}
\hline \multicolumn{1}{|c|}{ Objetos } & Quantidade & Preço (réis) & Observações \\
\hline & 1 & 800 & \\
\hline Termómetro & 5 & 240 & Muito usado \\
\hline Grais de pedra & 2 & 240 & \\
\hline Grais de marfim & 1 & 100 & \\
\hline Gral de vidro & 1 & 60 & \\
\hline Funil de vidro & 7 & 240 & \\
\hline Espátulas de pau & 1 & 120 & \\
\hline Espátula de marfim & 1 & 600 & Peso: arrátel \\
\hline Marco & 1 & 60 & \\
\hline Bacia de pó de pedra & 5 & 400 & Muito usado \\
\hline Peneiras & 1 & 80 & \\
\hline Sedaço & 1 & 80 & \\
\hline Crivo & 4 & 120 & Um de quartilho \\
\hline Copos deês de culix
\end{tabular}




\begin{tabular}{|c|c|c|c|}
\hline Objetos & Quantidade & Preço (réis) & Observações \\
\hline $\begin{array}{l}\text { Alambique para banho com dois } \\
\text { capacetes }\end{array}$ & 1 & 3.200 & \\
\hline Fogareiros de cobre & 3 & 10.000 & \\
\hline Bilha & 1 & 2.400 & \\
\hline Chocolateira & 1 & 120 & \\
\hline Tacho & 1 & 4.000 & \\
\hline \multicolumn{4}{|l|}{ Estanho } \\
\hline Pratos & 4 & 960 & \\
\hline Chocolateira & 1 & 160 & \\
\hline Comadres & 4 & 1.000 & \\
\hline Seringas & 2 & 280 & \\
\hline Bacia & 1 & 400 & \\
\hline Almofariz de chumbo & 1 & 400 & \\
\hline Esquentador & 1 & 300 & \\
\hline \multicolumn{4}{|c|}{ Arame ou Latão } \\
\hline Tacho & 8 & 8.000 & $\begin{array}{l}\text { Peso liquido: } 50 \\
\text { arráteis }\end{array}$ \\
\hline Colheres & 2 & 180 & \\
\hline Candeeiro & 1 & 200 & \\
\hline Candeia & 1 & 200 & \\
\hline Escumadeira & 1 & 160 & \\
\hline Seringa com sua caixa de madeira & 1 & 300 & \\
\hline Bacias com grade de madeira & 2 & 6.000 & \\
\hline Bilha & 1 & 600 & \\
\hline Bacias de barba & 2 & 480 & \\
\hline \multicolumn{4}{|c|}{ Roupa } \\
\hline Toalhas de linho para barba & 13 & 1.950 & \\
\hline Panos para a barba & 6 & 120 & \\
\hline \multicolumn{4}{|c|}{ Livros* } \\
\hline Farmacopéia Geral do Reino & 1 & & \\
\hline Farmacopéia Londinensis & 2 & & \\
\hline Farmacopéia de Pinto & 1 & & \\
\hline Farmacopéia de Bateme & 2 & & \\
\hline Farmacopéia Lisbonense & 1 & & \\
\hline Farmacopéia Tubalense & 1 & & $\begin{array}{l}\text { Segundo e tercei- } \\
\text { ro volumes }\end{array}$ \\
\hline
\end{tabular}




\begin{tabular}{|l|c|l|l|}
\hline \multicolumn{1}{|c|}{ Objetos } & Quantidade & Preço (réis) & Observações \\
\hline Farmacopéia Edinburgensis & 1 & & \\
\hline Farmacopéia Sueca & 1 & & \\
\hline Farmacopéia de Fuller & 1 & & \\
\hline Farmacopéia Dogmática & 2 & & \\
\hline Farmacopéia de Palacios & 1 & & \\
\hline $\begin{array}{l}\text { Farmacopéia de Tyrocenio, por } \\
\text { João Lauhes }\end{array}$ & 1 & & \\
\hline Farmacopéia Pauperum & 1 & & \\
\hline Farmacopéia Lusitana & 1 & & \\
\hline Farmacopéia de Lewis & 1 & & \\
\hline Farmacopéia de Baumé & 1 & & \\
\hline Farmacopéia Matritensis & 1 & & \\
\hline Farmacopéia de Peiros (?) & 1 & & \\
\hline Farmacopéia Augustana & 1 & & \\
\hline Farmacopéia de Wertenbergue & 1 & & \\
\hline Farmacopéia cirúrgica de Plenk & 1 & & \\
\hline $\begin{array}{l}\text { Farmacopéia Ulissiponense, por } \\
\text { João Vigier }\end{array}$ & 1 & & \\
\hline História de plantas, por João Vigier & 1 & & \\
\hline $\begin{array}{l}\text { Corpus Pharmaceutico Medicum, } \\
\text { por Jüngken }\end{array}$ & 1 & & \\
\hline $\begin{array}{l}\text { Enciclopédia cirúrgica racional, por } \\
\text { Doliz }\end{array}$ & 1 & & \\
\hline Matéria médica, por Pinto & 1 & & \\
\hline História de plantas, por Mattioli & 1 & & \\
\hline Historialogia médica, por Abreu & 1 & & \\
\hline Polyanthea medicinal, por Semedo & 1 & & \\
\hline $\begin{array}{l}\text { Dioscorides Anazarbeo por Legeme } \\
\text { [Laguna] }\end{array}$ & 1 & & \\
\hline Espécies de plantas, por Lineu & 2 volumes & & \\
\hline $\begin{array}{l}\text { Desengano para a medicina por } \\
\text { Kisler [Daniel Grislei] }\end{array}$ & 1 & & \\
\hline $\begin{array}{l}\text { Liber Singularis Medicamentorum, } \\
\text { por Pineate }\end{array}$ & 1 & & \\
\hline Ilustrações Médicas, por Saldanha & 1 & & \\
\hline Dicionário de Francês & 1 & & \\
\hline
\end{tabular}




\begin{tabular}{|l|c|c|c|}
\hline \multicolumn{1}{|c|}{ Objetos } & Quantidade & Preço (réis) & Observações \\
\hline $\begin{array}{l}\text { Thezorrus medico chimicus, por } \\
\text { Amenzih [Mynsicht] }\end{array}$ & 1 & & \\
\hline Conspectus medicinae, por Juncker & 1 & & Em oito volumes \\
\hline $\begin{array}{l}\text { Lexicon Chymico Pharmaceuticum, } \\
\text { por Jüngken }\end{array}$ & 1 & & \\
\hline Prosódia & 1 & & \\
\hline $\begin{array}{l}\text { Universal teatro pharma por } \\
\text { Desgorbis (?) [Sgobbis] }\end{array}$ & 1 & & \\
\hline Formulário magistral de codeto (?) & 1 & & \\
\hline
\end{tabular}

Fonte: Lisboa, A.N.T.T., MNEJ, caixa 225, maço 280.

*Não foi registada avaliação individual nem global. Em casos de leitura duvidosa (?)

Quadro 8. Convento de S. Sebastião da Ordem dos Pregadores (Setúbal)

\begin{tabular}{|c|c|c|c|}
\hline Objetos & Quantidade & Preço (réis)* & Observações \\
\hline Tachos & 7 & & Pequenos \\
\hline Tachos & 3 & & Grandes \\
\hline Alambiques de cobre & 2 & & \\
\hline Almofariz com mão de bronze & 1 & & \\
\hline Balanças & 3 & & \\
\hline Espátulas & 3 & & \\
\hline Colher de metal & 1 & & \\
\hline Grais de pedra & 4 & & \\
\hline Vasos de barro e vidro & 416 & & $\begin{array}{l}\text { Diversos taman- } \\
\text { hos }\end{array}$ \\
\hline Livros de farmacêutica & 29 & & \\
\hline Drogas & & 60.000 & $\begin{array}{l}\text { Quantidades não } \\
\text { especificadas }\end{array}$ \\
\hline
\end{tabular}

Fonte: Lisboa, A.N.T.T., MNEJ, caixa 225, maço 280.

* Os utensílios e livros que compunham a botica não foram avaliados individualmente. A avaliação global da botica foi de 79.310 réis a que houve que somar os 60.000 réis que importaram as drogas existentes. 
PARA O ESTUDO DA SAÚDE CONVENTUAL NO INÍCIO DO SÉCULO XIX: AS BOTICAS

Quadro 9. Convento Carmelitas Descalços de N. Senhora da Piedade (Cascais)

\begin{tabular}{|c|c|c|c|}
\hline Objetos & Quantidade & Preço (réis) & Observações \\
\hline Vasos de vidro & 222 & 44.400 & \\
\hline Açucareiros de vidro & 42 & 2.100 & \\
\hline Garrafas de vidro preto & 12 & 360 & \\
\hline Panelas de barro & 92 & 22.080 & \\
\hline Vasos de barro & 120 & 19.200 & \\
\hline Alambiques de cobre & 2 & 4.800 & \\
\hline Alambiques de folha com um capacete & 2 & 480 & \\
\hline Tachos de arame & 7 & 2.400 & $\begin{array}{l}\text { Entre pequenos e } \\
\text { grande }\end{array}$ \\
\hline Almofarizes de bronze & 2 & 20.600 & $\begin{array}{l}\text { Um grande e um } \\
\text { pequeno }\end{array}$ \\
\hline Almofarizes de marfim & 2 & 240 & \\
\hline Grais de pedra com suas mãos & 3 & 1.200 & \\
\hline Gral de vidro & 1 & 240 & \\
\hline Balanças & 4 & 9.600 & $\begin{array}{l}\text { Entre pequenos e } \\
\text { grande }\end{array}$ \\
\hline Marcos de bronze & 2 & 2.400 & Peso: arrátel \\
\hline Granatario & 1 & 200 & \\
\hline Medidas de latão e dois funis & & 2.400 & $\begin{array}{l}\text { Libra e meia } \\
\text { libra; onça e } \\
\text { meia onça } \\
\end{array}$ \\
\hline Espátulas & 4 & 120 & $\begin{array}{l}\text { Duas de latão e } \\
\text { duas de ferro }\end{array}$ \\
\hline Prensa & 1 & 800 & Muito arruinada \\
\hline Panelas de folha & 4 & 400 & \\
\hline Peneiros e Sedaços & 5 & 800 & \\
\hline Volumes de livros de diversos autores & 40 & 9.600 & \\
\hline Drogas & & 100.000 & $\begin{array}{l}\text { Quantidade não } \\
\text { especificada }\end{array}$ \\
\hline $\begin{array}{l}\text { Madeira de que se compõem as estan- } \\
\text { tes }\end{array}$ & & 100.000 & \\
\hline
\end{tabular}

Fonte: Lisboa, A.N.T.T., MNEJ, caixa 231, maço 285.

Recibido: 19 de diciembre de 2008.

Aceptado: 12 de octubre de 2009. 